\title{
Modificaciones al Régimen de las Iniciativas Privadas en la Ley de Asociaciones Público-Privadas(*)
}

\author{
Modifications to the Regime of Unsolicited Proposals in the Public Private \\ Partnerships Law
}

\author{
Milagros Maraví Sumar ${ }^{(*)}$ \\ Pontificia Universidad Católica del Perú (Lima, Perú)
}

\begin{abstract}
Resumen: La problemática investigada deriva de la experiencia de las iniciativas privadas en el Perú desde el año 2003 con la vigencia de la "Ley Marco de Promoción de la Inversión Descentralizada", ya que, su desarrollo y evolución amerita un recuento y análisis para proponer mejoras a esta figura, mediante la cual se han desarrollado relevantes proyectos de infraestructura, servicios públicos e inversión en activos estatales. Por ello, el objetivo del presente trabajo es abordar los principales problemas vinculados a las iniciativas privadas, como su errada vinculación con la corrupción; la problemática existente en relación al reembolso de gastos incurridos en la formulación y presentación de una iniciativa privada; los problemas presentados en la formulación de las mismas; $y$, finalmente, la naturaleza jurídica de la admisibilidad de las iniciativas privadas.
\end{abstract}

Palabras clave: Asociaciones público privadas - Iniciativas privadas cofinanciadas Iniciativas privadas autofinanciadas - Inversiones privadas - Derecho Administrativo

\begin{abstract}
The issue under investigation is limited to the experience of unsolicited proposals in Peru since 2003 with the implementation of the "Decentralized Investment Promotion Framework Law", which deserves a review and analysis to propose improvements to this figure, through which relevant infrastructure projects, public services and investment in state assets have been developed. Therefore, the objective of this work is to establish the main problems related to unsolicited proposals such as the disincentive to private investment due to corruption issues; the existing problems related to the reimbursement of expenses incurred in the formulation and presentation of unsolicited proposals; the problems presented in the formulation of such initiatives; and finally, the legal nature of the admissibility of unsolicited proposals.
\end{abstract}

Keywords: Public private partnerships - Co-financed unsolicited proposals - Selffinanced unsolicited proposals - Private Investment - Administrative Law

(*) Nota del Editor: Este artículo fue recibido el 22 de septiembre de 2020 y su publicación fue aprobada el 10 de noviembre de 2020 .

${ }^{* *}$ Abogada por la Pontificia Universidad Católica del Perú, socia que lidera el Área de Derecho Administrativo del Estudio Rubio, Leguía Normand. Máster en Administración Pública por el Instituto Ortega y Gasset adscrito a la Universidad Complutense de Madrid, con estudios en la Maestría de Gestión Pública de la Universidad Continental. Directora de la Corporación Financiera de DesarrolloCOFIDE. ORCID: https://orcid.org/0000-0003-0988-6664. Correo electrónico: mmaravi@rubio.pe 


\section{Introducción}

Las iniciativas privadas, unsolicited proposals (en inglés), son un mecanismo previsto en la legislación de numerosos países que sirve para que los inversionistas puedan identificar oportunidades de desarrollo de infraestructura y servicios públicos mediante una Asociación Público Privada - APPs o Inversión en Activos del Estado, que puedan ser de relevancia para las entidades públicas titulares de los mismos, que "en buena medida son una respuesta a las deficiencias observadas en la provisión tradicional de infraestructura pública" (Engel, Fischer \& Galetovic, 2014, p. 22); y a la vez puedan resultar rentables para el sector privado.

\section{Como señala Escaffi (2017) de manera muy didáctica:}

"Existen dos maneras de acceder a una APP: mediante iniciativa privada o por iniciativa pública. La diferencia radica en el origen del proyecto. El Banco Interamericano de Desarrollo define una iniciativa privada como "una propuesta enviada por iniciativa propia de la parte privada para realizar un proyecto de APP, en lugar de responder a una solicitud del gobierno" (Banco Interamericano de Desarrollo, 2011, p. 105).

Todas estas definiciones tienen en común el que estamos ante proyectos de infraestructura o de servicios públicos o activos de titularidad del Estado sobre los que usualmente el Estado planifica, formula, estructura, adjudica y ejecuta o contrata su ejecución. Sin embargo, cuando existe esta figura, el sector privado puede identificar proyectos y presentarlos ante las entidades públicas para el análisis de su prioridad y relevancia.

Por su parte, Morón (2008) indica que:

"Por la figura de las iniciativas privadas se reconoce a los integrantes de la comunidad, la facultad de participar en la labor de identificar y proponer al Estado estudios sobre posibilidades innovativas de infraestructura, servicios públicos o emprendimientos sobre recursos públicos, que siendo de interés empresarial del proponente, también puedan ser prioritarias para el interés público, esto es, proyectos socialmente rentables, sostenibles y concordantes con las políticas y lineamientos del Estado" (p. 150).

Esta definición incide en la innovación del proyecto, aspecto que nos parece muy relevante, ya que las Inversiones Privadas (en adelante "IPs") no deberían limitarse a cubrir las carencias de planeamiento o formulación de las entidades públicas, sino privilegiarse en el espacio de la innovación.

Desde el Decreto Legislativo 758 - Ley de Promoción de la Inversión Privada en Infraestructura de Servicios Públicos, publicado el 8 de noviembre de 1991, se reconocía en el país expresamente la potestad de presentar iniciativas privadas ${ }^{(1)}$. Dicho texto fue modificado por el Decreto Legislativo 839 - Ley de Promoción de la Inversión Privada en Obras Públicas de Infraestructura y de Servicios Públicos, publicado el 20 de agosto de 1996, para limitar sus alcances ${ }^{(2)}$ a casi solo una legitimación para presentar sugerencias de proyectos a las entidades públicas. En ese período no se desarrollaron iniciativas privadas.

Es recién el 2003, con la Ley 28059 Ley Marco de Promoción de la Inversión

\section{(1) Decreto Legislativo 758}

Artículo 11. Las personas jurídicas podrán presentar iniciativas que identifiquen el proyecto a contratar, señalando sus lineamientos generales que contendrán, como mínimo, las bases de su factibilidad económica y técnica. Dichos lineamientos, tienen carácter confidencial y reservado.

Cuando el organismo concedente considere que el proyecto antes indicado y su ejecución se adaptan al procedimiento de concesión podrá optar entre licitar su ejecución o promover un concurso de proyectos integrales, guardando la confidencialidad de quien tuvo la iniciativa y de los demás participantes.

En cualesquiera de los dos supuestos, concluido el procedimiento respectivo, de existir una oferta más conveniente que la presentada por quien tuvo la iniciativa, el autor de dicha iniciativa y el de la oferta considerada más conveniente, podrán mejorar sus respectivas propuestas.

En el caso que las propuestas presentadas sean igualmente convenientes, se preferirá la del que tuvo la iniciativa.

(2) Texto del artículo 11 del Decreto Legislativo 758 con la modificación del Decreto Legislativo 839

"Las personas jurídicas nacionales o extranjeras podrán presentar únicamente ante la PROMCEPRI, a manera de sugerencias, lineamientos generales de proyectos integrales que permitan a esa Comisión informarse sobre posibles obras públicas de infraestructura o de servicios públicos susceptibles de entregarse en concesión al sector privado, según lo dispuesto por el presente Decreto Legislativo. Una vez analizadas tales sugerencias, y previa opinión favorable del Comité Especial respectivo, el cual introducirá las ampliaciones o modificaciones que juzgue convenientes, los indicados proyectos podrán eventualmente sujetarse a los procesos de promoción de la inversión privada en el marco del presente Decreto Legislativo. La recepción, análisis, ampliaciones o modificaciones y decisiones que sobre tales sugerencias pueda adoptar la PROMCEPRI no establecen compromiso alguno de esa Comisión para con las personas que presentaron la sugerencia respectiva, en futuras convocatorias a Licitación o Concurso". Quedan modificados los artículos contenidos en el Capítulo Segundo -De las Iniciativas- del Decreto Supremo N 189-92-PCM en todo aquello que se oponga a este nuevo texto del artículo 11 del Decreto Legislativo 758. 
Descentralizada LMID ${ }^{(3)}$, que se presentan y tramitan iniciativas privadas con la particularidad que se podía tratar de proyectos en los tres niveles de gobierno (Nacional, Regional y Local). Este régimen estuvo vigente hasta la aprobación en el 2008 del Decreto Legislativo 1012 - Ley Marco de Asociaciones Público-Privadas para la Generación de Empleo Productivo, que delimitada las IPs a solo aquellas autofinanciadas ${ }^{(4)}$. Con la Ley 29771, Ley que modifica el primer párrafo del artículo 14 del Decreto Legislativo 1012, publicada el 2 de julio de 2011 , se eliminó tal limitación ${ }^{(5)}$, pero esa disposición nunca fue reglamentada.

La Ley de Presupuesto del 2013, Ley 29951, incluye una disposición complementaria final que prioriza las inversiones privadas cofinanciadas (IPCs) destinadas a cubrir el déficit de infraestructura y servicios públicos, conjuntamente, que serían presentados y tramitados por PROINVERSIÓN. El 23 de enero de 2013 se reglamentó dicha norma estableciendo que estas IPCs serían desarrolladas mediante contrato de concesión. Bajo ese marco jurídico se presentaron casi 200 IPs a PROINVERSIÓN.

El Decreto Legislativo 1224, del Marco de Promoción de la Inversión Privada mediante Asociaciones Público Privadas y Proyectos en Activos, y el marco legal actual, admiten IPs autofinanciadas y cofinanciadas con un tratamiento diferenciado. Así, las iniciativas privadas cofinanciadas (en adelante IPCs) se presentan a solicitud de las entidades en proyectos que estas definen y en período de "ventanas"; es decir, que no se trata en puridad de iniciativas privadas; mientras las iniciativas privadas autofinanciadas (en adelante IPAs) sí pueden presentarse en cualquier momento y sobre materias no definidas con anticipación. Las IPCs deben ser sobre proyectos previstos en el Informe Multianual de Inversiones en APPs - IMIAPPs y los proyectos de las IPAs se incorporan a él una vez que son declaradas de relevancia y prioridad. Los montos mínimos para una IPA son menores que los de una $\mathrm{IPC}^{(6)}$.

En ambos casos, si se presentan uno o más terceros interesados, se abre un concurso abierto a otros terceros, conforme lo establece el artículo 38 del Decreto Legislativo 1362, Decreto Legislativo que Regula la Promoción de la Inversión Privada mediante Asociaciones Público Privadas y Proyectos en Activos $^{(7)}$; y el artículo 90 de su Reglamento aprobado por el Decreto Supremo 240-2018-EF(8). Existe el derecho a igualar por parte del proponente, pero, adicionalmente, un desempate entre ambos.

(3) Publicada en el Diario Oficial El Peruano el 13 de agosto de 2003.

(4) Decreto Legislativo 1012:

Artículo 14. De la naturaleza de las iniciativas privadas Las iniciativas privadas se realizan sobre proyectos de inversión en activos, empresas, proyectos, servicios, obras públicas de infraestructura y de servicios públicos, las mismas que no podrán demandar garantías financieras y se sujetarán a lo establecido por el acápite ii del literal a del artículo 4 del presente Decreto Legislativo.

(5) Decreto Legislativo 1012:

Párrafo modificado por el artículo 1 de la Ley № 29771, publicada el 27 julio 2011, cuyo texto es el siguiente: "Artículo 14. De la naturaleza de las iniciativas privadas Las iniciativas privadas se realizan sobre proyectos de inversión en activos, empresas, proyectos, servicios, obras públicas de infraestructura y de servicios públicos".

(6) 7,000 o 10,000 UITs vs 15,000 UITs

(7) Artículo 38. Criterios para la incorporación de los proyectos al proceso de promoción

38.1 El proceso de promoción está conformado por las fases de Estructuración y Transacción. El Reglamento establece los requisitos, plazos y criterios de elegibilidad de los proyectos a ser incorporados al proceso de promoción.

38.2 El Consejo Directivo de Proinversión aprueba la incorporación de proyectos al proceso de promoción; sin que ello limite modificaciones posteriores al proyecto, las cuales son debidamente sustentadas.

38.3 El Reglamento establece los supuestos en los que la incorporación de proyectos al proceso de promoción a cargo de Proinversión es ratificada mediante Resolución Suprema refrendada por el Ministro del sector respectivo y por el Ministro de Economía y Finanzas. Lo dispuesto en este numeral no se aplica a los supuestos previstos en los artículos 43 y 51 , así como en el Subcapítulo V del presente Capítulo. 38.4 En los proyectos de alcance regional o local, la incorporación es realizada mediante Acuerdo de Consejo Regional o Acuerdo de Concejo Municipal, respectivamente.

(8) Artículo 90. Proceso de selección en iniciativas privadas

$90.1 \mathrm{Si}$ dentro del plazo previsto en el artículo 88 concurren uno o más terceros interesados en la ejecución del mismo proyecto objeto de la IP, el OPIP, al término del plazo, debe cursar una comunicación escrita al proponente, poniendo en su conocimiento la existencia de terceros interesados en el proyecto e iniciar el correspondiente proceso de selección, para lo cual procede a elaborar las Bases. 90.2 El proceso de selección es realizado de acuerdo a lo establecido en las Bases, las cuales incluyen la información publicada en la DI, incorporando los Niveles de Servicio, las especificaciones técnicas mínimas, y en caso lo determine el OPIP, la posibilidad de presentación de propuestas técnicas que empleen tecnologías o soluciones técnicas diferentes, que garantice la competencia, devolviendo la carta fianza entregada por el proponente de la IP.

90.3 En caso el proponente no participe en el proceso de selección que se convoque, pierde el derecho a solicitar el reembolso de los gastos en los que hubiese incurrido en la preparación de la propuesta. 
En ese sentido, el presente trabajo tiene por finalidad realizar un análisis sobre las principales problemáticas derivadas de la evolución y experiencia de la figura de las iniciativas privadas en el Perú a lo largo de estos últimos años.

Por ello, y con el objetivo de proponer mejoras a esta figura mediante la cual se han desarrollado relevantes proyectos de infraestructura, servicios públicos e inversión en activos estatales; se analizarán los principales problemas vinculados con las IPs, tales como su asociación con corrupción; los inconvenientes en relación al reembolso de gastos incurridos en la formulación y presentación de una IP; la demora en la formulación de los proyectos de inversión (PIPs) en las IPCs; $\mathrm{y}$, finalmente sobre la naturaleza jurídica de la admisibilidad de las IPs.

\section{La vinculación de las IPs con la corrupción}

Como señalan Benavente y Segura, en la mayoría de países los proyectos de APP se originan por iniciativa estatal y algunos países ni siquiera han considerado las iniciativas privadas (2017, p. 41). Estos mismos autores señalan que si bien: "las IPs pueden contribuir con ideas de proyectos nuevos, así como soluciones creativas e innovadoras más costo eficientes" (Benavente \& Segura, 2017, p. 41), enfrentan complejos retos vinculados a su articulación con los planes y presupuestos multianuales de las entidades públicas, ya que pueden incrementar el riesgo de lobbies y percepción cierta o no de corrupción y las ventajas del proponente, respecto de información, la limitada ventana de competencia y el derecho a igualar pueden dificultar que se genere competencia, mayor valor por dinero y se maximice el beneficio a los usuarios.

Es obvio que las IPs están pensadas como un mecanismo complementario y marginal al planeamiento del Estado en esta materia. Así, a primera vista, parece muy conveniente dejar ese espacio de colaboración en el planeamiento público al sector privado que luego se extenderá al menos a la formulación, máxime cuando el Estado ha demostrado su limitada capacidad para emprender ambas tareas. De hecho, varios de los riesgos anotados por los autores antes citados no se han verificado en el concurso de la IPC del Sistema de tratamiento de las aguas residuales de la cuenca del Lago Titicaca, en la cual existieron cinco postores de alto nivel, incluido el proponente y el adjudicatario fue un tercero interesado cuya oferta resulto $30 \%$ por debajo del monto estimado de inversión del proyecto.

Ya advertíamos el 2013 que este mecanismo en Perú generaba desconfianza respecto de que los proyectos estén formulados solo para ser un buen negocio para el proponente y que, solo en un número muy reducido de casos se adjudicaban por concurso, pues no concurrían terceros interesados (Maraví, 2013, p. 92). En ese sentido, en Perú se han presentado los problemas que se advierten en otros países ${ }^{(9)}$. Estos problemas son más alarmantes si se verifican en IPs cofinanciadas, en las cuales la inversión e inclusive el mantenimiento se repagan con recursos del Estado.

No son desdeñables ambas atingencias, menos si a estas alturas del devenir de las APPs en Perú nos encontramos con investigaciones respecto de corrupción en proyectos que se originaron como IPs con reconocimiento explícito de empresas corruptas del pago de coimas.

Benavente y Segura afirman que:

Una fuente documentada de contingencias al Estado y de perjuicios a los usuarios se originó por el incumplimiento de las entidades de solicitar la opinión previa del MEF en el caso de los contratos surgidos por iniciativas privadas consideradas autofinanciadas que, sin embargo, no lo eran (2017, p. 53).

Como ejemplo de ello citan, sin embargo, un caso de APPs y no de IPs, el de los corredores complementarios del sistema integrado de Transporte de Lima (SIT):

El proceso excepcional para permitir la regularización voluntaria de contratos y

90.4 En caso que la Buena Pro para la ejecución del proyecto fuera otorgada al titular de una propuesta distinta a la del proponente de la IP, se reintegran al proponente los gastos en los que hubiera incurrido conforme a lo señalado en el artículo 93 del presente Reglamento y el artículo 48 de la Ley.

(9) A este respecto, se sugiere revisar el documento Política de gestión de iniciativas privadas en proyectos de infraestructura Vol I Principales hallazgos y recomendaciones, II Lineamientos para el desarrollo de una política de gestión de iniciativas privadas en proyectos de infraestructura y III Revisión de Experiencias de Iniciativas privadas.

https://ppiaf.org/documents/5377

https://ppiaf.org/documents/5430

https://ppiaf.org/documents/5431 
adendas que no hubiesen contado con la opinión previa favorable del MEF, mediante Decreto de Urgencia 006-2015, permitió que estos fueran remitidos al MEF para opinión. Ninguno era autofinanciado. En la mayoría de casos se realizaron modificaciones que permitieron que se volvieran realmente autofinanciados (Benavente \& Segura, 2017, p. 54).

Si por incapacidad técnica o por corrupción se desarrollan proyectos que no serían desarrollados según el interés público, es conveniente revisar los mecanismos de su génesis. Asimismo, si casi ninguna IP da lugar a un concurso que asegure que el principio de competencia(10) ${ }^{(10}$ verifique, más aun, es indispensable tal revisión. Los recursos del Estado son limitados y el déficit de infraestructura y servicios públicos creciente.

Es conveniente, sin embargo, no perder de vista que la corrupción ha calado lo mismo en APPs. Así, los contratos de los corredores complementarios citados por Benavente y Segura (2017), son producto de APPs y no de IPs. Asimismo, los principales procesos cuestionados dentro del caso "lava jato", tales como las interoceánicas o gasoducto del sur, también son APPs, que se suman a proyectos por obra pública tales como Vía Costa Verde - tramo Callao, Vía de Evitamiento de Cusco y Línea 1 del Metro. También otras APPs ahora cuestionadas como la del Aeropuerto de Chinchero se originaron por iniciativa estatal. Es decir, que el origen como IP no ha sido el derrotero de la corrupción, porque tanto en APPs como en IPs se ha verificado este problema.

Mi hipótesis es que, como en muchos otros casos, por enfrentar estos problemas, se ha introducido cambios al régimen de las IPs que terminan desincentivando la inversión privada. Es decir, nos hemos ido de un extremo permisivo a un extremo prohibitivo, y si bien el título de este documento sugiere modificaciones legales, tengo muy claro que las reformas normativas solas logran poco y pueden tender a generar una indeseada inseguridad jurídica respecto del régimen vigente. Esto ocurrió, por ejemplo, con aquellas iniciativas privadas que se presentaron bajo el régimen de la Nonagésima Sexta Disposición Complementaria Final de la Ley 29951 - Ley de Presupuesto del Sector Público para el Año Fiscal 2013 y el Decreto Legislativo 1012, que se tuvieron que adaptar al Decreto Legislativo 1224 y luego al Decreto Legislativo 1362.

De hecho, en las IPAs más relevantes del ámbito nacional, no se discute la necesidad de los proyectos y ha habido varios terceros interesados: es el caso de la IPA de PTAR
Taboada ${ }^{(11)}$, que se presentó bajo la Ley Marco de Inversión Descentralizada, Ley 28059, y pasó a adjudicarse conforme al Decreto Legislativo 1012 el año 2009, a uno de los dos terceros interesados, el 26 de febrero de 2009. Igualmente, el 1 de diciembre de 2006 se presentó la IPA PTAR La Chira. El 4 de julio de 2008 se publicó la Declaratoria de Interés, presentándose cinco terceros interesados, uno de los cuales se adjudicó la buena pro el 18 de noviembre de 2010.

Asimismo, la IPA Aguas de Lima Sur II "AGUAS DE LIMA SUR II ", que fue presentada en julio de 2008, la Declaratoria de Interés fue publicada el 8 de enero de 2011 y se presentaron siete terceros interesados. Se realizó el Concurso de Proyectos Integrales para la entrega en concesión del Diseño, Financiamiento, Construcción, Operación y Mantenimiento del Proyecto que fue cancelado sin expresión de causa en enero de 2012. Sin embargo, el proyecto fue adjudicado posteriormente en otro concurso denominado PROVISUR con gran cantidad de competidores. Todos estos proyectos muy necesarios y vigentes.

Del mismo modo se encuentra la IPC de la PTAR Titicaca, la cual fue presentada ante PROINVERSIÓN el 16 de mayo de 2014 y cuya Declaratoria de Interés fue publicada el 21 y 22 de marzo de 2018. Adjudicándose la Buena Pro del Concurso de Proyectos Integrales para la entrega en concesión de la PTAR Titicaca, a uno de los cinco postores interesados, en 29 de abril de 2019.

$\mathrm{Si}$ bien en otros proyectos como el de Terminal Portuarios Salaverry, solo hubo un tercero interesado y se realizó concurso entre el proponente y aquel, igualmente hubo espacio para competencia. La IPA (originalmente para un muelle de concentrados), se presentó el 1 de febrero de 2012, a iniciativa de la APN, el 6 de mayo de 2015 se presentó reformulada la IPA como

(10) Decreto Legislativo 1224:

Artículo 4. Principios

En todas las fases vinculadas al desarrollo de los proyectos regulados en el presente Decreto Legislativo se aplican los siguientes principios:

a) Competencia Los procesos de promoción de la inversión privada promueven la búsqueda de competencia, igualdad de trato entre los postores y evitan conductas anticompetitivas o colusorias.

(11) Se presentó a PROINVERSIÓN el 31 de octubre de 2006. 
"Iniciativa Privada para la Modernización y Desarrollo del Terminal Portuario Multipropósito de Salaverry", el 4 de agosto de 2017 se publicó la declaratoria de interés, presentándose un tercero interesado y, finalmente, el 31 de mayo de 2018, se adjudicó la Buena Pro del Concurso de proyectos integrales para la entrega en concesión del Proyecto "Modernización y Desarrollo del Terminal Portuario Multipropósito de Salaverry", al proponente.

Es en las IPAs de proyectos de inversión en activos en los que mayormente no ha habido terceros interesados y se han adjudicado al proponente directamente; por ejemplo: en la IPA para adquirir tierras del proyecto especial Jequetepeque Zaña ${ }^{(12)}$, la IPA para el Desarrollo Agroexportador en Tierras Eriazas de Supe ${ }^{(13)}$. Sin embargo, en el conocido caso de la IPA del Sol de Collique, sí hubo dos terceros interesados, lo cual devino en una disputa judicial por el proyecto que finalmente fue adjudicado al proponente.

En la web de PROINVERSIÓN, se puede encontrar una cartera importante de IPAs presentadas, entre ellas viales, portuarias, de saneamiento, de inversión en activos que han derivado algunas en concurso y adjudicaciones. Sin embargo, la mayoría de iniciativas privadas concluidas, han sido rechazadas. De 62 que figuran en la web de PROINVERSIÓN, solo 12 han sido adjudicadas y se ha suscrito contrato. En 6 casos se han desistido los proponentes, en 1 se ha adjudicado, pero no se suscribió el contrato y en los demás (43) han sido rechazadas o dejadas sin efecto.

Es en el ámbito municipal, concretamente en la Municipalidad Metropolitana de Lima que, en el mismo período, se desarrollaron 3 IPAs viales muy visibles: (i) el proyecto vial Línea Amarilla (Ahora Vía Parque Rímac) presentado a la MML el 31 de marzo de 2009, (ii) "Vías nuevas de Lima" y (iii) "Vía Expresa Sur"; los tres adjudicados directamente porque no se presentaron terceros interesados. En los dos primeros, se suscribieron los contratos de concesión y están en ejecución; sin embargo, con el caso "lava jato" también ha sido blanco de acusaciones de corrupción. En el último caso no se ha suscrito contrato, porque la etapa de cierre del proceso se extendió por años, la IPA no llegó a adaptarse a la nueva normativa de APPs y, finalmente, por el caso "lava jato", la nueva gestión de la MML decidió no firmar el contrato de concesión.

En resumen, las IPs no son privilegiadamente mecanismos utilizados para llevar adelante proyectos que se señalan como afectados por la corrupción más que las APPs por iniciativa estatal. La corrupción ha afectado por igual a todos los mecanismos de contratación del Estado, lo cual ha manchado todos los mecanismos de contratación con el Estado. No se requieren medidas específicas ni más contundentes anti corrupción en las IPs que en la contratación estatal en general.

Asimismo, como hemos afirmado previamente, las IPs deberían ser usadas para promover la innovación en el planeamiento, formulación y ejecución de proyectos del Estado, no principalmente para suplir las carencias del Estado en estas funciones que, de ser el caso deberían remontarse.

\section{La problemática relacionada con el reembolso de gastos en las IPs}

Una de las expectativas de los proponentes de IPs es que los gastos de elaboración y de formulación del proyecto de la IP le sean reembolsados si no es adjudicatario. Así, en un blog del Banco Mundial sobre este aspecto(14), se formula una sugerente pregunta:"It is fair to reimburse the studies? There is no such thing as a 'free meal'?" (Neves, Samos \& Motolese, 2018).

La respuesta que se da a esta pregunta es que si bien consideran más conveniente que los estudios los desarrolle el Estado para evitar posibles ventajas estratégicas que distorsionen la competencia; si se encarga los estudios al privado, éste espera una compensación, y como el Gobierno debería tener una clara idea del costo del desarrollo de esos estudios, debería suscribir un acuerdo con el privado en el que se pre acuerden los gastos a reembolsar, como es el caso del Estado de Virginia (Neves, Samos \& Motolese, 2018).

Conforme reconoce la doctrina, las inversiones que realizan los particulares para formular y presentar una iniciativa privada son merecedoras de protección por parte del

(12) El 6 de diciembre de 2007 IPA para adquirir tierras del proyecto especial Jequetepeque Zaña y se publicó la Declaratoria de Interés y el 5 de febrero.

(13) Dos de diciembre de 2007 se presentó la IPA para el Desarrollo Agroexportador en Tierras Eriazas de Supe y el 31 de enero de 2009 se publicó la declaratoria de interés.

(14) Extraído de: https://blogs.worldbank.org/ppps/unsolicited-proposals-infrastructure-balancing-act-between-incentives-vs-competition 
ordenamiento jurídico (Expósito \& Santos, 2010, p. 136). De ahí que los ordenamientos jurídicos que fomentan la participación del sector privado en la provisión de infraestructura pública y servicios públicos establezcan diversos incentivos que tienen por objeto alentar tal participación:

Existen diversas formas de incorporar el régimen de iniciativas en los procedimientos de selección. En el caso de la doctrina uruguaya y argentina se han logrado encontrar los mecanismos necesarios para la promoción de las iniciativas privadas mediante los siguientes mecanismos:

- Sistema de bonos o de derecho de preferencia, en el cual el iniciador (proponente de la iniciativa privada) "cuenta con una ventaja por sobre el resto de los oferentes en el proceso de selección, la cual consiste en que su oferta será la adjudicada, salvo que resulte superada por otra en un porcentaje determinado previamente".

- Sistema de segunda vuelta o balotaje mediante el cual "se permite al iniciador, junto con el oferente que presentó la mejor propuesta en el procedimiento de selección, mejorar sus ofertas; ello permite que el iniciador mejore la propuesta inicialmente formulada".

- Reembolso del costo del proyecto, en cuyo caso, "el incentivo consiste en garantizarle al iniciador que se le retribuirá el proyecto objeto de la iniciativa; en el caso de no resultar adjudicatario del procedimiento de selección".

- Plazo de duración, lo que significa una garantía para el iniciador, es decir, consiste en establecer "un plazo, dentro del cual dicho iniciador pueda hacer valer los beneficios derivados de la autoría de su proyecto" [énfasis agregado] (Martin, 2008, pp. 25-26).

En sentido similar Expósito y Santos señalan:

Según lo enseñan experiencias internacionales, esa protección puede consistir en 1. una especie de compensación económica ó 2. en beneficios dentro del procedimiento de selección, tales como preferencias en caso de empate o puntos adicionales en la calificación de la propuesta. No obstante, como se advierte en los ejemplos citados a continuación, la protección más común se refiere a la compensación económica por la elaboración de los estudios [énfasis agregado] (2010, p. 136).

Aunado a ello, Vilcanqui (2012) invoca además un criterio de justicia respecto del proponente de una IPC como sustento o justificación del reembolso de los gastos incurridos por un particular en la formulación y presentación de una iniciativa privada:

Por otro lado, consideramos importante indicar que la creatividad empleada en una iniciativa privada es susceptible de valorización económica y atribuible a una empresa o consorcio. El tiempo que duró la investigación del negocio, la estrategia para hacer que funcione, los estudios de ingeniería, los estudios legales y demás forman parte del proceso creativo del empresario interesado en un activo, bien o servicio del Estado. Lo justo sería reconocer su esfuerzo y la propiedad de la iniciativa, en caso el proponente no

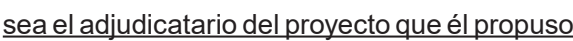
[énfasis agregado] (p. 299)(15).

Conforme a lo expuesto, el reembolso de los gastos incurridos en la formulación y presentación de una IPC, constituye no solo un incentivo, sino también una protección a los particulares que formulan y presentan una iniciativa privada.

En el Perú, desde el Decreto Legislativo 1012, se reconoce el reembolso de los gastos efectuados por el proponente de una IP. El mismo texto ha reiterado en las normas siguientes y hasta la actualidad que se debería reconocer: (i) los gastos efectivamente realizados; (ii) que sean directamente vinculados con el proyecto; (iii) que sean razonables; y (iv) debidamente sustentados.

Ello se confirma en la Directiva 004-2019-PROINVERSIÓN - Gestión de Iniciativas Privadas ${ }^{(16)}$, aprobada por Acuerdo de Consejo Directivo PROINVERSIÓN 931-2019-CD, publicado el 1 de diciembre de 2019; donde se señala en el punto 20 referido al Reembolso de Gastos al Proponente, que se procederá al reembolso de "gastos efectivamente realizados" al proponente cuando éste presente una propuesta económica declarada válida en el proceso de promoción.

Sin embargo, en la realidad, el derecho al reembolso se ha visto limitado por interpretaciones de las normas que no son razonables ni han sido informadas previamente a los proponentes respecto de: (i) qué se entiende por gastos efectivamente realizados; y (ii) cuáles se consideran directamente vinculados en la elaboración de la iniciativa privada y los estudios de preinversión. Esto a pesar que legalmente se ha fijado un límite a los gastos reembolsables que es de $1 \%$ del monto del proyecto en caso de IPAs y $2 \%$ en caso de IPCs.

Respecto del primer tema, las normas de APPs no definen lo que debe entenderse por "gastos efectivamente realizados" y, en el caso de personas jurídicas, es necesario remitirnos a las normas contables que

(15) El numeral 48.2 del artículo 48 de la vigente Ley de APPs contiene la misma previsión.

(16) Extraído de: https://www.proyectosapp.pe/RepositorioAPS/0/2/JER/ANEXOS_DIRECTIVA_GESTION_IP/Directiva.pdf 
establecen los criterios para reconocer cuando ha incurrido en un gasto por una operación.

Para tal efecto, debe tomarse en cuenta que el artículo 223 de Ley General de Sociedades ("LGS") establece la obligatoriedad de que los estados financieros de las sociedades establecidas en el país se preparen y presenten de conformidad con las normas legales y los "Principios de Contabilidad Generalmente Aceptados". En ese sentido, resulta claro que la información financiera debe ser elaborada siguiendo las pautas y criterios establecidos en las NIC que hayan sido oficializadas a través del Consejo Normativo de Contabilidad.

Al respecto, el párrafo "OB 17" del Marco Conceptual para la Información Financiera dentro de la sección denominada "Rendimiento financiero reflejado por la contabilidad de acumulación (o devengo)" señala que:

La contabilidad de acumulación (o devengo) describe los efectos de las traxnsacciones y otros sucesos y circunstancias sobre los recursos económicos y los derechos de los acreedores de la entidad que informa en los periodos en que esos efectos tienen lugar, incluso si los cobros y pagos resultantes se producen en un periodo diferente (Consejo de Normas Internacionales de Contabilidad) [énfasis agregado] (2010, p.9).

Del mismo modo, el párrafo 4.49 del Marco Conceptual indica que:

Se reconoce un gasto en el estado de resultados cuando ha surgido un decremento en los beneficios económicos futuros, relacionado con un decremento en los activos o un incremento en los pasivos, y además el gasto puede medirse con fiabilidad. En definitiva, esto significa que tal reconocimiento del gasto ocurre simultáneamente al reconocimiento de incrementos en las obligaciones o decrementos en los activos (por ejemplo, la acumulación o el devengo de salarios, o bien la depreciación del equipo) (Consejo de Normas Internacionales de Contabilidad) [énfasis agregado] (2010, p. 24).

Como puede verse, bajo una interpretación a la luz de la norma contable, debe entenderse que los "gastos efectivamente realizados" a los que aluden las normas de APP, serán aquellos gastos devengados, independientemente de que estos hayan sido pagados o cancelados.

Sin embargo, debido a que la norma tributaria no contiene una definición del concepto de devengado, el Tribunal Fiscal ha considerado también necesaria una remisión al criterio adoptado por la contabilidad. En efecto, en reiterados pronunciamientos, tales como en las Resoluciones del Tribunal Fiscal 06710-3-2015 y 05378-3-2015, se ha establecido el siguiente criterio:

Que asimismo este Tribunal ha indicado en la Resolución Nº $02812-$ 2-2006, entre otras, que el concepto de devengado supone que se hayan producido los hechos sustanciales generadores del ingreso y/o gasto y que el compromiso no esté sujeto a condición que pueda hacerlo inexistente, siendo que el hecho sustancial generador del gasto o ingreso se origina en el momento en que se genera la obligación de pagarlo o el derecho a adquirirlo, aun cuando a esa fecha no haya existido el pago efectivo, lo que supone una certeza razonable en cuanto a la obligación y a su monto.

(...)

Que en ese sentido, los elementos determinantes para definir el ejercicio al que se imputará el gasto son determinar que se hayan producido los hechos sustanciales generadores del gasto originado en el momento en que se genera la obligación de pagarlo, aun cuando a esa fecha no haya existido el pago efectivo; que el compromiso no esté sujeto a condición que pueda hacerlo inexistente y que esté sustentado en un comprobante de pago en el caso que exista la obligación de emitirlo; no siendo un condicionante para su devengo, ni la fecha en que se emitió o recibió dicho comprobante de pago, ni la fecha de su registro contable. [énfasis agregado]

Finalmente, en doctrina también se ha seguido la misma línea para reconocer las operaciones en las que incurre una empresa. Así, por ejemplo, sobre el principio de lo devengado, Enrique Jorge Reig (1991), señala que:

Ingreso devengado es, entonces, todo aquel sobre el cual se ha adquirido el derecho de percibirlo por haberse producido los hechos necesarios para que se genere. Correlativamente en cuanto a los gastos, se devengan cuando se causan los hechos en función de los cuales, terceros adquieren derecho al cobro de la prestación que los origina [énfasis agregado] (p. 288).

Añade el citado autor, que el concepto tiene estas características:

1. Requiere que se hayan producido los hechos sustanciales generadores del ingreso o del gasto.

2. Requiere que el derecho al ingreso o compromiso de gasto no esté sujeto a condición que pueda hacerlo inexistente.

No requiere actual exigibilidad o determinación, ni fijación de término preciso para el pago; puede ser obligación a plazo y de monto no determinado [énfasis agregado] (1991, p. 289).

De igual modo, García Mullín (1980) señala lo siguiente:

Tratándose de gastos, el principio de lo devengado se aplica considerándoseles imputables (deducibles) cuando nace la 
obligación de pagarlos, aunque no se hayan pagado, ni sean exigibles [énfasis agregado] (p. 46).

Como puede verse, bajo una interpretación a la luz de la norma contable, tributaria y doctrina debe entenderse que los "gastos efectivamente incurridos o que hubiera incurrido" a los que aluden las normas de APPs peruanas desde la vigencia del Reglamento del Decreto Legislativo 1012, serán aquellos gastos devengados, independientemente de que estos hayan sido pagados o cancelados.

Una interpretación distinta sería lesiva para cualquier proponente, porque el bien o servicio en cuyo gasto se ha incurrido se ha utilizado para la IP y se entrega al Estado para su aprovechamiento, lo cual puede ser verificado con la misma IP entregada o los estudios técnicos o de preinversión entregados.

Asimismo, por ejemplo, en la práctica comercial, es común que los gastos derivados de servicios prestados por los proveedores se cancelen a plazos (i.e. 60, 90, 120 días). Esto, sin embargo, no implica en absoluto que el servicio no haya sido provisto y que, por lo tanto, el gasto no haya sido incurrido. En ese sentido, limitar el reconocimiento de los gastos a aquellos cancelados a la fecha de presentación de la declaración atenta contra las normas contables y tributarias que son las que las empresas consideran al invertir en una IP.

Por último, si la intención del legislador hubiese sido únicamente que se reconozcan los gastos "efectivamente pagados", este requisito debió haberse contemplado de forma expresa en los artículos pertinentes, lo que no sucede en el Decreto Legislativo 1362 ni en su Reglamento. Concluir lo contrario, devendría en una interpretación arbitraria e ilegal de nuestro ordenamiento jurídico y una pésima señal para inversionistas que apuestan por el desarrollo de infraestructura y servicios en el país.

En ese sentido, todos los gastos devengados presentados en las respectivas declaraciones juradas deben ser reconocidos como gastos del proponente a ser reembolsados conforme al artículo 48 del Decreto Legislativo 1362 y en el artículo 93 del Decreto Supremo 240-2018-EF.

Sin embargo, el criterio que aplica PROINVERSIÓN es el de que los gastos deben estar efectivamente pagados y no solo incurridos y exige la prueba del pago y respectivo pago de impuestos por el proveedor.

Respecto de cuáles son los gastos efectivamente incurridos en la elaboración de la iniciativa privada y los estudios de preinversión, también se dan otras interpretaciones restrictivas. Así, es más difícil que se reembolsen los gastos del equipo interno de las empresas que preparan la IP que si es esta tarea encargada y facturada a un tercero. Esta posición es contraproducente, porque el proponente prefiere tercerizar la preparación de la IP para que le sea facturada y así no se le discutan esos gastos, en lugar de realizarlo con su equipo interno que sí cuenta con el expertise requerido y acreditado al presentar la IP.

Asimismo, muchas veces, las entidades públicas solicitan que el proponente realice gastos necesarios para los estudios técnicos del proyecto, pero que son de responsabilidad de ella, por ejemplo, temas de estudios de diagnóstico, actividades de saneamiento o titulación predial y el Estado se niega a reconocerlos como reembolsables.

El artículo 48 de la ley de APPs - Decreto Legislativo 1362, reconoce el reembolso de gastos a favor del proponente de la IPC que ha venido realizando gastos para elaborar el estudio de preinversión y, particularmente, en el artículo 48.4. se prevé la posibilidad de que la entidad titular del proyecto adquiera los estudios realizados por el proponente, a fin de utilizarlos para continuar con el proyecto como APP de iniciativa estatal(17). Es decir que, si la entidad titular del proyecto decide descartar la IPC y continuar el proyecto por iniciativa pública, puede adquirir los estudios trabajados por el proponente.

Sin embargo, no reconoce qué ocurre cuando la entidad decide rechazar la IP y (i) no realizar el proyecto o (ii) realizarlo mediante otro mecanismo distinto a APP. Estos supuestos también deberían estar previstos, pues el proponente ha realizado inversiones en la elaboración del estudio de preinversión y en la preparación de la IPC, tales como recursos humanos, económicos y técnicos altamente calificados, así como la

(17) Decreto Legislativo 1362

Artículo 48. Reembolso de gastos a favor del proponente

(...)

48.4 En caso que, por supuestos distintos a los establecidos en el numeral precedente, la iniciativa privada no continúe, la entidad titular del proyecto está facultada para adquirir los estudios realizados por el proponente, a través del Organismo Promotor de la Inversión Privada, a fin de utilizarlos para continuar con las fases de desarrollo de la Asociación Público Privada mediante iniciativa estatal, sin que ello suponga un retroceso a fases previas. 
experiencia e información cuya propiedad intelectual y secreto comercial es del proponente y no puede ser usada por el Estado, salvo que lo adquiera del proponente.

A este respecto, es conveniente tener presente lo advertido por Morón (2008):

En nuestra consideración no es posible hablar de propiedad intelectual sobre el objetivo de la iniciativa (la necesidad pública de infraestructura o servicios identificada por el iniciador aunque aquella necesidad aun no haya sido definida formalmente por la administración) ni sobre el tipo de objeto sobre el que recaerá el contrato a provocarse con la iniciativa (la construcción de una obra determinada o la prestación del servicio mismo).

Pero sí existe propiedad intelectual, que debe ameritar un tratamiento diferenciado de confidencialidad y preservación del privilegio del iniciador cuando la propuesta no solicitada suponga la aplicación de nuevos conceptos, tecnologías o procesos industriales que disponga el titular de la iniciativa y redunden en mejora del proyecto.

(...)

Este paso inventivo consistirá en una metodología, técnica o forma de hacer las cosas creativas e individualizables, distinta a la forma actual en que se realiza la actividad, de modo que amerite reconocer la propiedad intelectual del proponente sobre la iniciativa. Por el contrario, no procederá la consideración de originalidad o innovación, la forma de gestión que se limita a la forma común de construir una obra, o prestar un servicio, ni tampoco el ofrecimiento de cumplimiento de estándares legales de prestación de servicios o construcción de obras (pp. 167-168).

Al respecto, es cierto que existe un tipo de creación que es considerada propiedad intelectual del proponente de una IP; sin embargo, más allá de esto, los estudios técnicos y económicos de una IPA o el estudio de preinversión de una IPC son indiscutiblemente de propiedad del proponente también en todo aquello que no sea de su propiedad intelectual. Como consecuencia de ello, es que se le reembolsa los mismos y, de ser el caso, si se deniega la IP, los estudios son devueltos al proponente y la información no puede ser usada por la entidad estatal, salvo que los adquiera.

Conforme a lo anterior, el reembolso de gastos al proponente debería proceder aun cuando sus sobres 1 o 2 no sean válidos, pero los presente. En efecto, el marco normativo peruano condiciona el reembolso a la presentación de una oferta económica válida y si el proponente no presenta sobres 1 y 2 válidos se verá impedido de presentar una oferta económica válida; y, por lo tanto, no se reconocerá su reembolso de gastos. No sólo eso, su carta fianza de seriedad de oferta será ejecutada, a pesar de que su oferta económica es devuelta sin ser siquiera revisada su validez por el Organismo Promotor de la Inversión Privada (OPIP) de la entidad a cargo del proceso de APP.

Sabemos que el objetivo de estas normas es asegurar que el Proponente participe en el Concurso y éste, al presentar sobres Nro. 1 y 2 , manifiesta su intención de hacerlo. Si el proponente ha participado del Concurso tal y como requiere la Ley de APPs, no puede serle exigible un requisito que le es imposible de cumplir, al no abrirse su Sobre Nro. 3 de propuesta económica por una decisión adoptada por el OPIP. En consecuencia, el requisito del artículo 48 de la Ley de APPs consistente en la presentación de una propuesta económica declarada válida, será aplicable siempre y cuando el Sobre Nro. 3 sea abierto. El artículo 48 no se ha puesto en el caso que los sobres 1 o 2 no sean aceptados y, al tratarse de un derecho del proponente, su interpretación no debería ser restrictiva de tal derecho al reembolso.

De otro lado, debe tenerse presente que, al haberse precisado el monto de los gastos a reembolsar en la Declaratoria de Interés de la IP, dicho monto ha sido considerado por los postores para formular sus respectivas ofertas. Por tanto, dicho monto ya ha sido internalizado por el Adjudicatario del Concurso, que es el obligado a realizar el pago conforme lo establece la Declaratoria de Interés. Concluir lo contrario implica adoptar una decisión contraria al principio de razonabilidad ${ }^{(18)}$ que manda: "Mantener la proporción entre los medios y fines. Quiere decir que la autoridad al decidir el tipo de gravamen a emitir o entre diversos grados que una misma sanción puede conllevar, no tienen plena discrecionalidad para la opción, sino que debe optar por aquella que sea proporcional a la finalidad perseguida por la norma legal" $(2018$, p. 88). Sería totalmente desproporcionado negarle el derecho de reembolso al Proponente por haberle rechazado sus Sobres Nro. 1 o 2, lo cual, además, ordinariamente no se considera impugnable.

(18) TUO de la LPAG aprobado por Decreto Supremo 004-2019-JUS Artículo IV.

1.4. Principio de razonabilidad. - Las decisiones de la autoridad administrativa, cuando creen obligaciones, califiquen infracciones, impongan sanciones, o establezcan restricciones a los administrados, deben adaptarse dentro de los límites de la facultad atribuida y manteniendo la debida proporción entre los medios a emplear y los fines públicos que deba tutelar, a fin de que respondan a lo estrictamente necesario para la satisfacción de su cometido. 
Si las normas de APP buscan promover que los privados presenten IPs, inviertan en realizar los estudios de preinversión y el proyecto sea finalmente adjudicado, debe tenerse presente que el punto 2 del artículo IV del TUO de la LPAG establece que:

Los principios señalados servirán también de criterio interpretativo para resolver las cuestiones que puedan suscitarse en la aplicación de las reglas de procedimiento, comoparámetros para la generación de otras disposiciones administrativas de carácter general, y para suplir los vacíos en el ordenamiento administrativo". Es decir, no es optativa su aplicación.

Lo anterior también es consecuente con el principio de Enfoque de Resultados, previsto en el artículo 4 inciso 3 de la Ley de APPs que dispone que:

Entre dos o más alternativas legalmente viables, se debe optar por la que permita la ejecución del proyecto en los plazos correspondientes, la que promueva la inversión, la que permita alcanzar o mantener los niveles de servicio del proyecto o la que resulte más conveniente en términos de costos, eficiencia o sostenibilidad [énfasis agregado].

Por otro lado, el proponente, conforme a las Bases, cumple con presentar una Garantía al iniciarse el Concurso que tiene por objeto asegurar la presentación de los Sobres Nro.1, Nro.2 y Nro.3 por parte de los Postores. En el caso del Proponente, esta Garantía es adicional al incentivo de participación que tiene él como tal para ser adjudicatario u obtener el reembolso de los gastos de preparación de la IPC y de la formulación.

Sin embargo, usualmente el texto de la Carta Fianza prevé unos supuestos de ejecución de la misma entre los que se encuentra el que el Postor Precalificado: "No cumpla con presentar una oferta económica válida en el proceso de selección convocado". En ese sentido, el texto aludido presupone para la ejecución que el Postor Precalificado: (i) ha presentado Sobres Nro. 2 y Nro.3; (ii) el Sobre Nro.2 ha sido aceptado; (iii) el Sobre Nro.3 se abre; y (iv) la oferta económica contenida en el Sobre Nro. 3 no se ajusta a lo establecido en las Bases. En este supuesto, si el postor no presenta un sobre 1 válido, no existirá un postor precalificado y si no presenta sobre 2 válido, no se abrirá su sobre 3 para verificar su conformidad $y$, en los dos casos, se ejecutará la fianza.

En ambos supuestos, no debería ejecutarse la fianza, sino proceder a devolverla al proponente, tal y como se efectuó en el Concurso de Proyectos Integrales para la Concesión de Obras Hidráulicas Mayores del Proyecto Chavimochic y el Concurso de Proyectos Integrales para la
Entrega en Concesión del Segundo Grupo de Aeropuertos Regionales de la República del Perú. En ambos casos, se presentó el supuesto de postores precalificados cuyo Sobre Nro. 2 fue descalificado y por tanto no se procedió a la apertura del respectivo Sobre Nro. 3 , sin que ello originara o diera lugar a la ejecución de la Garantía ${ }^{(19)}$.

Finalmente, resulta ilustrativo el criterio del ente rector del Sistema Nacional de Promoción de la Inversión Privada, respecto a la ejecución de la carta fianza que otorga el proponente de una iniciativa privada o de un proyecto en activo, con motivo de la Declaratoria de Interés. En efecto, en el párrafo final del Oficio 066-2018-EF/68.01, la Dirección General de Política de Promoción de la Inversión Privada, refiriéndose a la no suscripción del contrato en caso de adjudicación directa, señala que la ejecución de la carta fianza procederá cuando se deba a causas imputables al proponente:

Sin perjuicio de lo anterior, cabe señalar que, en caso la no suscripción del contrato se deba a causas imputables al proponente, serán de aplicación las garantías que este hubiera otorgado, de conformidad con lo dispuesto en el artículo 46.3 del Reglamento del Decreto Legislativo 1224, o garantías equivalentes (2018, p. 5).

Conforme se puede apreciar, el ente rector aplica un criterio de imputabilidad o no de las causas que determinan, en el caso de la consulta, la no suscripción de un contrato derivado de una iniciativa privada.

Aplicando el mismo criterio, no consideramos que pueda ejecutarse una carta fianza cuya causal de ejecución es la no presentación de una oferta económica válida, si el sobre 3 no llega abrirse por resultar desaprobados los sobres $1 \circ 2$, decisiones que son inimpugnables.

Otro tema vinculado al derecho al reembolso está relacionado a la titularidad

(19) Acta de anuncio del Resultado de la evaluación del Sobre Nro. 2, apertura del Sobre Nro. 3 y adjudicación de la buena pro, de fecha 18 de diciembre de 2013, correspondiente al Concurso de Proyectos Integrales para la Concesión de Obras Hidráulicas Mayores del Proyecto Chavimochic.

Así mismo, Acta de Apertura del Sobre Nro. 3 y Adjudicación de la Buena Pro, de fecha 7 de setiembre de 2010, correspondiente al Concurso de Proyectos Integrales para la Entrega en Concesión del Segundo Grupo de Aeropuertos Regionales de la República del Perú. 
de quién tiene derecho al reembolso. Es usual que, a lo largo del procedimiento de tramitación de una IP, el proponente pueda sufrir modificaciones en su conformación. Por ello, es en la declaratoria de interés que reconoce el reembolso al proponente por los costos de elaboración de la IP y, en el caso de las cofinanciadas, también los costos del estudio de preinversión u otros adicionales por solicitud de modificaciones de la IP por iniciativa del Estado.

Sin embargo, el proponente original puede ser una persona jurídica individual y luego consorciarse con otra empresa y finalmente hasta el proponente original puede cambiar integrantes por completo. Es recién con el Reglamento del Decreto Legislativo 1224, aprobado por Decreto Supremo 410-2015-EF, que se regula expresamente la modificación del proponente, lo que se reitera en el Reglamento del Decreto Legislativo 1362, aprobado por Decreto Supremo 240-2018-EF, estableciendo lo siguiente:

Artículo 92. Modificación de los integrantes del proponente

92.1 El proponente de la IP puede realizar modificaciones a su conformación, siempre que mantenga o mejore su capacidad técnica o financiera.

92.2 La modificación del proponente puede ser efectuada hasta antes de la suscripción del Contrato. En estos casos, el proponente formula su solicitud de modificación ante el OPIP, acompañando los documentos que la sustentan. EI OPIP responde dicha solicitud en un plazo máximo de diez (10) días hábiles de recibida.

92.3 Además de lo dispuesto en el presente artículo, en caso se presenten terceros interesados, la modificación del proponente se realiza conforme lo establezcan las Bases.

Sin embargo, los OPIP han tramitado modificaciones de proponente de IPAs muchas veces antes de la existencia de estas normas. No así en el caso de las IPC, en cuyo caso PROINVERSIÓN mantuvo a los proponentes por meses a la espera de la definición de cuál sería el trámite y requisitos para su reconformación. En ese sentido, muy probablemente los acuerdos privados entre las empresas para asumir gastos de la IPC sean previos a la aprobación de modificación de proponente de PROINVERSIÓN y hayan determinado la realización de gastos del proyecto por parte de una o más empresas que no son formalmente parte del proponente.

Ante este supuesto, causado por su propia demora, en el caso de la IPC del Sistema de tratamiento de las aguas residuales de la cuenca del Lago Titicaca, PROINVERSIÓN ha denegado el reconocimiento como reembolsables de casi la mitad de los costos incurridos por una empresa que no era parte del proponente desde el inicio y que no pudo incorporarse el Proponente por la demora de PROINVERSIÓN en permitir el inicio del trámite de modificación de proponente y solo consideró reembolsables aquellos gastos efectuados desde esa aprobación, bajo el argumento de que "cualquier documento privado no resulta vinculante para el Sector Público y específicamente para PROINVERSION". Esta afirmación no se ajusta al marco legal vigente que no establece ninguna formalidad de los documentos de sustento ni proscribe de ninguna manera que el sustento de los gastos sea por medio de un documento privado suscrito con anterioridad a su presentación a PROINVERSION.

De hecho, todos los contratos de proveedores que podrían sustentar los gastos y que originan las facturas presentadas son contratos privados suscritos previamente a su presentación ante PROINVERSION. La norma no exige formalidades determinadas para sustentar los gastos ni que sean presentados a la fecha de su celebración o tengan fecha cierta. No existe ningún ordenamiento especial que le niegue absolutamente valor vinculante a un documento privado. Sin embargo, es posible que la ley exija ciertos requisitos o formalidades a los documentos a ser presentados, lo cual no ocurre en las normas de APPs. Además de ello, tampoco se exige esta formalidad en el contrato de consorcio del proponente con el cual para el procedimiento para la modificación del proponente.

Para darle mayor abundamiento a esta posición, es pertinente indicar que de conformidad con los "Lineamientos para la presentación y Admisión a Trámite de las Iniciativas Privadas Cofinanciadas", publicados por PROINVERSION, solo se requiere una copia simple del documento por el cual se conforma un Consorcio Proponente y no se exige la fecha cierta.

El Consorcio Proponente no tiene personalidad jurídica y, por lo general, tampoco contabilidad separada, y por lo tanto los gastos son efectuados por cada empresa integrante del Consorcio y esa es la razón por la cual cada empresa presenta el sustento de los gastos incurridos por cada una de ellas.

El Texto Único Ordenado de la Ley de Procedimiento Administrativo General, aprobado por Decreto Supremo 0042019-JUS establece en su artículo 40.4, que las entidades sólo pueden exigir a los administrados el cumplimiento de procedimientos, la presentación de documentos o el suministro de información 
que estén establecidos por decreto supremo o norma de mayor jerarquía y que incurre en responsabilidad la autoridad que procede de modo diferente, realizando exigencias a los administrados fuera de estos $\operatorname{casos}^{(20)}$.

Ni el Decreto Legislativo 1362 ni su Reglamento exigen que los documentos de sustento de gastos tengan determinadas formalidades o siquiera que sean de fecha cierta para efectos de verificar su preexistencia.

Esto es explicable, pues la Ley del Procedimiento Administrativo General, que es el estándar mínimo para todos los demás procedimientos, incluyendo los procedimientos especiales, según el artículo II de la misma norma ${ }^{(21)}$, se rigen por principios como el de razonabilidad, presunción de veracidad, eficacia y simplicidad(22).

No es razonable que se pretenda desconocer documentos privados o se les exija formalidades a los documentos a presentar para el sustento de gastos que no son exigibles legalmente y los administrados no pueden ser sorprendidos con la exigencia de formalidades no requeridas por una norma. Si así estuviera establecido, el administrado sabría de inicio qué formalidades deben cumplir los documentos.

En efecto, si se trata de comprobantes de pago, corresponde que el proponente cumpla con las normas aplicables a los mismos. No es el caso de los documentos privados que no tienen formalidades exigibles ni se limita el reconocimiento de sus efectos a partir de la fecha de su presentación a la entidad.

La incidencia en que los gastos hayan sido efectivamente realizados, tiene su principal comprobación en los estudios que conforman el estudio de preinversión. En ese sentido, únicamente en situaciones expresas en que la norma exige alguna formalidad, ésta debe cumplirse.

Así, por ejemplo, tenemos el literal d) del numeral 6.1 del artículo 4 del Reglamento de Comprobantes de Pago aprobado por Resolución de Superintendencia 007-99/ SUNAT, determina que en caso en el cual existan contratos de arrendamiento o de cesión del uso de inmuebles y el usuario del mismo hace uso de los servicios públicos asignados al inmueble pero en los recibos figure el nombre del propietario, es posible que se pueda utilizar el crédito fiscal contenido en ellos con una condición, la cual

(20) Artículo 40.- Legalidad del procedimiento

(...)

40.3 Los procedimientos administrativos deben ser compendiados y sistematizados en el Texto Único de Procedimientos Administrativos, aprobados para cada entidad, en el cual no se pueden crear procedimientos ni establecer nuevos requisitos, salvo lo relativo a la determinación de los derechos de tramitación que sean aplicables de acuerdo a la normatividad vigente.

40.4 Las entidades solamente exigen a el cumplimiento de procedimientos, los la administrados presentación de documentos, el suministro de información o el pago por derechos de tramitación, siempre que cumplan con los requisitos previstos en el numeral anterior. Incurre en responsabilidad la autoridad que procede de modo diferente, realizando exigencias a los administrados fuera de estos casos.

(21) Artículo II.- Contenido 1. La presente Ley contiene normas comunes para las actuaciones de la función administrativa del Estado y, regula todos los procedimientos administrativos desarrollados en las entidades, incluyendo los procedimientos especiales. 2. Las leyes que crean y regulan los procedimientos especiales no podrán imponer condiciones menos favorables a los administrados que las previstas en la presente Ley. 3. Las autoridades administrativas, al reglamentar los procedimientos especiales, cumplirán con seguir los principios administrativos, así como los derechos y deberes de los sujetos del procedimiento, establecidos en la presente Ley. (Texto modificado según el artículo 2 del Decreto Legislativo 1272)

(22) Principios

1.4. Principio de razonabilidad. Las decisiones de la autoridad administrativa, cuando creen obligaciones, califiquen infracciones, impongan sanciones, o establezcan restricciones a los administrados, deben adaptarse dentro de los límites de la facultad atribuida y manteniendo la debida proporción entre los medios a emplear y los fines públicos que deba tutelar, a fin de que respondan a lo estrictamente necesario para la satisfacción de su cometido.

1.7. Principio de presunción de veracidad. En la tramitación del procedimiento administrativo, se presume que los documentos y declaraciones formulados por los administrados en la forma prescrita por esta Ley, responden a la verdad de los hechos que ellos afirman. Esta presunción admite prueba en contrario.

1.10. Principio de eficacia. Los sujetos del procedimiento administrativo deben hacer prevalecer el cumplimiento de la finalidad del acto procedimental, sobre aquellos formalismos cuya realización no incida en su validez, no determinen aspectos importantes en la decisión final, no disminuyan las garantías del procedimiento, ni causen indefensión a los administrados.

En todos los supuestos de aplicación de este principio, la finalidad del acto que se privilegie sobre las formalidades no esenciales deberá ajustarse al marco normativo aplicable y su validez será una garantía de la finalidad pública que se busca satisfacer con la aplicación de este principio.

1.13. Principio de simplicidad. Los trámites establecidos por la autoridad administrativa deberán ser sencillos, debiendo eliminarse toda complejidad innecesaria; es decir, los requisitos exigidos deberán ser racionales y proporcionales a los fines que se persigue cumplir. 
está referida a que si en el contrato de arrendamiento o de cesión del inmueble las firmas de las partes intervinientes se encuentran legalizadas ante Notario.

Otro caso es el previsto por el literal s) del numeral 1.3 del artículo 21 del Reglamento de la Ley del Impuesto a la Renta que establece que la donación de bienes podrá ser deducida como gasto cuando la donación conste en un documento de fecha cierta.

Por lo tanto, cuando no existe formalidades establecidas por la propia disposición legal, no cabe la posibilidad que se exijan formalidades adicionales para reconocer la validez de un Contrato de Consorcio, en el cual se sustenta el que los gastos de la IP sean asumidos, por acuerdo del proponente original, en partes iguales por ambas empresas integrantes del Consorcio.

La denegatoria de reembolso apelando a exigencia de formalidades que son previstas en la Ley de APPs o su Reglamento es un acto de confiscación.

\section{La demora existente en la formulación de las IPCs}

De las IPCs presentadas el 2013, 2014, 2015 y 2016 siguen en evaluación las siguientes IPCs ${ }^{(23)}$ :

- 10 de saneamiento presentadas, 1 el 2015, 8 el 2017 y 1 el 2018.

- 5 de colegios del 2014 y 1 del 2015.

- 2 de hospitales del 2014 y 1 del 2015.

- 1 víal y otra de residuos hospitalarios del 2013.

De todas ellas, solo se encuentra en estructuración la IPC del "ANILLO VIAL PERIFÉRICO". Las demás están en formulación. ¿Cómo así la etapa de formulación de las IPCs puede tomar 5 a 6 años? De hecho, varias más que estaban en formulación han sido objeto de desistimiento o rechazo.

Algunas de las causas relevantes son las siguientes:

a) Se ha realizado en algunos casos un cambio en la unidad formuladora cuando el marco normativo autorizó a que PROINVERSIÓN trasladara la misma a las entidades titulares del proyecto;

b) Se realizó un cambio de Gobierno por elecciones generales y sucesivos relevos de Ministros en Educación, salud y Vivienda, Saneamiento y también cambios en las gestiones regionales y municipales. Cada uno de esos cambios de gestión determinó un análisis de si los proyectos continuarían o no, como si no fueran parte del planeamiento estatal; c) Las normas técnicas que sustentan la formulación fueron aprobadas paralelamente a la misma, determinando la paralización de la formulación hasta la aprobación de tales normas;

d) La Directiva que regula la formulación de las IPCs, Directiva 001-2014-EF/63.01 aprobada mediante Resolución Directoral 002-2014-EF/63.01(24), prevé una formulación con evaluación concurrente por hitos, eso incrementa los espacios para adopción de aprobaciones por parte de la entidad que, en lugar de haber agilizado los procesos los ha entrampado;

e) Los equipos a cargo de la formulación cambian y son inexpertos en temas de APPs y aplican a la formulación de APPs los "tarifarios" de construcción de la ley de contrataciones.

El impacto en las IPCs ha sido de desmotivación absoluta por parte de los proponentes que pasan años invirtiendo sin saber si el proyecto continuará, si les serán reconocidos los gastos reembolsables y si el proyecto será adjudicado para llevarlo adelante o que opere el reembolso efectivamente.

Por otro lado, no es entendible para qué se requiere la elaboración de estudios de preinversión si, como en el caso de la IPC del Sistema de tratamiento de las aguas residuales de la cuenca del Lago Titicaca, se optó por convocar a un concurso de proyectos integrales en el que los postores podían presentar cualquier solución alternativa a la de la formulación. En ese supuesto, debería evitarse el gran gasto de la formulación y con estudios preliminares ir a un concurso. Si ya existe formulación realizada conjuntamente con el Estado en al que se estudia las alternativas y se opta por la más eficiente, esa debería concursarse.

Si la formulación es un proceso conjunto entre la entidad y el proponente y se formula lo que el proponente requiere, debería convocarse a concurso de proyectos integrales el proyecto formulado.

(23) Véase https://www.proyectosapp.pe/modulos/JER/PlantillaStandard.aspx?are=0\&prf=0\&jer=60 38\&sec=22 pestaña "en evaluación".

(24) Extraído de http://www.ipd.gob.pe/images/documentos/normas/asociaciones/Directiva_N_001-2014-EF-63.01.pdf 
Por otro lado, PROINVERSIÓN, asumimos que, para facilitar la presentación de terceros interesados, viene exigiendo a éstos fianzas que equivalen a la tercera parte de la exigida al proponente de la IP. Esto no es recomendable porque puede terminar trayendo al concurso a postores que no tienen la solvencia requerida. Las fianzas deberían ser iguales.

\section{La naturaleza jurídica de las IPs como petición de gracia}

La Ley establece que las IPs son peticiones de gracia, así se señala en el inciso 5 del artículo 45 del Decreto Legislativo 1362:

45.5 Las iniciativas privadas tienen el carácter de peticiones de gracia, de acuerdo con lo establecido en el artículo 121 del Texto Único Ordenado de la Ley $N^{\circ} 27444$, Ley del Procedimiento Administrativo General, aprobado por Decreto Supremo $N^{\circ} 006-$ 2017-JUS, en lo que sea pertinente. En consecuencia, el derecho del proponente se agota con la presentación de la iniciativa privada ante el Organismo Promotor de la Inversión Privada, sin posibilidad de cuestionamiento o impugnación del pronunciamiento en sede administrativa o judicial. Las iniciativas privadas mantienen su carácter de petición de gracia hasta que se convoque el proceso de selección que corresponda, en cuyo caso, es de aplicación lo dispuesto en las respectivas bases y/o en la legislación respectiva, en lo que sea pertinente; o hasta la suscripción del contrato correspondiente, en caso se adjudique directamente por no haber terceros interesados.

¿Cuáles son los requisitos de admisibilidad de una IP? Básicamente están relacionados al cumplimiento de requisitos objetivos que están previstos en el Reglamento de la Ley de APPs y, para el caso de las IPCs, en los Lineamientos para la presentación y admisión a trámite de las Iniciativas Privadas Cofinanciadas, aprobados por PROINVERSIÓN ${ }^{(25)}$.

El artículo 77 del Reglamento de la Ley de APPs los describe:

- El nombre o razón social del solicitante, con indicación de sus generales de ley, acompañando los correspondientes poderes del representante legal.

- Estados financieros auditados de los últimos dos (02) años que demuestren la capacidad financiera del proponente de la IP.

- Certificados o constancias emitidas por terceros distintos a la persona jurídica acreditada, que sustenten la capacidad técnica y la experiencia del proponente para el desarrollo de proyectos de similar envergadura.

- La declaración jurada de los gastos efectivamente incurridos en la elaboración de la IP presentada.
- La propuesta de cláusulas principales del Contrato.

- El modelo económico financiero del proyecto propuesto.

- Los estudios técnicos.

Para el caso de las IPC se requiere, adicionalmente detallar (i) los beneficios sociales del proyecto y (ii) la proyección anual de financiamiento.

Para el caso de las IPA se presenta, asimismo: (i) análisis técnico del proyecto; (ii) análisis de la demanda por el servicio que brinda el proyecto; (iii) estimación de costos de supervisión; (iv) evaluación económica financiera preliminar del proyecto como APP; (v) estimación preliminar de los riesgos; y (v) plan de implementación del proyecto.

Como ya lo he señalado desde el 2014, la etapa de admisibilidad de una IP no se puede considerar como una petición de gracia, ya que se trata de verificar el cumplimiento o no de los requisitos de admisibilidad. En ese sentido, la decisión sobre la admisibilidad sí debe ser impugnable por reconsideración o apelación. Lo que es petición de gracia es la declaración de no relevancia o prioridad o de no interés (Maraví, 2014, pp. 115-116).

Luego de la admisibilidad, dado que en las IPs existe una inversión realizada por los proponentes y no se trata de un trámite en el que el administrado queda a la espera de una respuesta del Estado a manera de concesión de gracia, cada etapa debería ser de obligatoria consecución para las entidades.

Así, si una entidad declara de relevancia e interés una IP, debería estar obligado a culminar la etapa de formulación y si el proyecto es viable, debería estar obligada a concluir la etapa de estructuración hasta la declaratoria o no de interés. Igualmente, si declara de interés, la entidad debería estar obligada a adjudicar y firmar contrato, salvo cancelación del concurso o licitación debidamente sustentada. En la actualidad, el único efecto de que una entidad abandone un proyecto es que tenga que reembolsar a PROINVERSIÓN los gastos del procedimiento(26).

(25) Véase http://www.proyectosapp.pe/modulos/JER/PlantillaStandard.aspx?are=0\&prf =2\&jer=8137\&sec=22

(26) Decreto Legislativo 1362: 


\section{Conclusiones}

Es conveniente que exista en la normativa peruana de APPs un espacio para las IPs, principalmente para aprovechar la innovación en la provisión de la infraestructura, servicios públicos y proyectos en activos.

La corrupción no se ha verificado en mayor medida en las IPs que en otros mecanismos de contratación del Estado, así que no se requiere medidas ad hoc para las IPs. Sin embargo, debería acudirse a ellas principalmente por la innovación y no por carencias en la formulación de proyectos de las entidades públicas.

Las IPCs deben siempre estar previstas en los IMIAPPs, no así las IPAs, para lo cual se debería realizar una modificación en el artículo 40 del Reglamento del Decreto Legislativo 1362; sin embargo, el impacto presupuestal de aquellos recursos que no se consideran cofinanciamiento tales como los requeridos para expropiaciones o interferencias, deben ser identificados y evaluados antes de su declaratoria de relevancia.

Los gastos reembolsables deben calcularse en función del criterio contable de devengado, que es el que aplican las empresas a sus gastos. El debido sustento de los gastos principalmente es el estudio mismo de preinversión en las IPCs y los estudios que componen la IPA. Para ello es necesario una modificación de los artículos 75 (para IPCs) y el artículo 93 (para las IPAs), del Reglamento del Decreto Legislativo 1362.

El reembolso no debe estar condicionado a la presentación de una oferta económica válida en el concurso o licitación. El reembolso debe operar porque el proponente es propietario de los estudios y participa en el concurso precalificando y presentando propuesta técnica y económica. Menos aún debe ejecutarse su garantía de seriedad de oferta. Asimismo, el reembolso debería reconocerse al proponente al momento de la declaratoria de interés respecto de toda la inversión realizada por quienes formen o hayan formado parte del proponente y desde la preparación de la IP.

En las IPCs la formulación de un estudio de preinversión solo debería ser obligatoria si no se convocará a un concurso de proyectos integrales, en el que cada postor puede proponer su alternativa de lograr los niveles de servicio, porque la formulación pierde sentido. Si la formulación se realiza, debe ser bajo las normas regulares de INVIERTE. $\mathrm{PE}$, no por evaluación concurrente, porque demora la formulación. En ese sentido, ello debería estar especificado en el artículo 108 del Reglamento del Decreto Legislativo 1362.

La etapa de evaluación de admisibilidad de una IP, no puede ser considerada una petición de gracia; sólo las etapas posteriores. Esas etapas, por la inversión involucrada, deberían ser de obligatoria consecución. En el caso de las IPCs, el proyecto no puede abandonarse por cambio de gestión ya que está en el IMIAPP de la entidad. A razón de ello, resulta necesaria una modificación en el artículo 45 del Decreto Legislativo 1362.

\section{Referencias bibliográficas}

Benavente, P. \& Segura, A. (2017). Luces y sombras del modelo de APP en la experiencia peruana. En P. Benavente, J. Escaffi, A. Segura \& J. Távera (eds.), Las Alianzas Público-Privadas (APP) en el Perú: Beneficios y Riesgos (pp. 20-61). Plataforma para la Reflexión Política.

Consejo de Normas Internacionales de Contabilidad. (2010). Marco Conceptual para la Información Financiera. Recuperado de https:// www.mef.gob.pe/contenidos/conta_publ/con_nor co/vigentes/nic/ES_GVT_BV2017_conceptual.pdf.

Dirección General de Política de Promoción de la Inversión Privada. (2018). Oficio 066-2018/ EF/68.01. Recuperado de; https://www.mef. gob.pe/contenidos/inv_privada/normas/app/ oficio_066_2018EF6801.pdf

Engel, E., Fischer, R. \& Galetovic, A. (2014) Economía de las asociaciones público-privadas: Una guía básica ( $1^{\text {a }}$ ed.). Fondo de Cultura Económica México.

Escaffi, J. (2017). APP: contrato de largo plazo entre el Estado y el sector privado al servicio de las personas. En P. Benavente, J. Escaffi, A. Segura \& J. Távera (eds.), Las Alianzas Público-Privadas

Artículo 12. Proinversión

12.9 Proinversión aplica mecanismos disuasivos a las entidades públicas titulares de proyectos, para evitar que abandonen sus proyectos en cartera, entre ellos, el reembolso de los gastos incurridos por Proinversión.

Decreto Supremo 240-2018-EF:

Artículo 27. Mecanismos disuasivos en caso de abandono de proyectos

27.3 En caso de que la entidad pública titular del proyecto no atienda de manera adecuada el requerimiento formulado por Proinversión, este último puede proceder con la aplicación conjunta de los siguientes mecanismos disuasivos:

2. Requerir el reembolso de la totalidad de los gastos generados, deduciendo aquellos gastos, pagos o transferencias que Proinversión haya recibido en virtud del referido proyecto. 
(APP) en el Perú: Beneficios y Riesgos (pp. 104115). Plataforma para la Reflexión Política.

Expósito, J. \& Santos, J. (2010). La iniciativa privada en las concesiones de infraestructura y servicios públicos. Revista Digital de Derecho Administrativo, 3, 85-154.

García, J. (1980). Manual del Impuesto a la Renta. Instituto de Capacitación Tributaria.

Martin, R. (2008). Las iniciativas privadas en el proceso de promoción de la inversión privada en el Perú. Revista Peruana de Derecho Administrativo Económico, 2, 15-42.

Maraví, M. (2013). Las iniciativas privadas cofinanciadas. Revista de Derecho Administrativo, 13, 91-102.

Maraví, M. (2014). Marco legal de las Iniciativas Privadas Cofinanciadas vigentes desde setiembre de 2014. Advocatus, 30, 109-119. https://doi. org/10.26439/advocatus2014.n030.4277

Morón, J. (2008). Las concesiones de infraestructura a iniciativa del inversionista. Revista Peruana de Derecho Administrativo Económico, 2, 149-185.

Morón, J. (2018). Comentarios a la Ley del Procedimiento Administrativo General (Tomo I). Gaceta Jurídica.

Neves, P., Samos, J. \& Motolese, G. (2018). Iniciativas privadas en proyectos de infraestructura: un desafío para encontrar el equilibrio entre incentivos y competencia. Banco Mundial Blogs. https:// blogs.worldbank.org/es/ppps/iniciativas-privadas-en-proyectos-deinfraestructura-un-desaf-o-para-encontrar-el-equilibrio-entre.

Reig, E. (1991). Impuesto a las Ganancias. Ediciones Macchi.

Tribunal Fiscal del Ministerio de Economía y Finanzas (2015, 03 de enero) Resoluciones del Tribunal Fiscal 05378-3-2015.

Tribunal Fiscal del Ministerio de Economía y Finanzas. (2015, 10 de julio) Resoluciones del Tribunal Fiscal 06710-3-2015.

Vilcanqui, P. (2012) Las iniciativas privadas en proyectos de inversión: creatividad, ¿cuándo limitar y cuándo no? Revista de Derecho Administrativo, 12(1), 291-300. 
